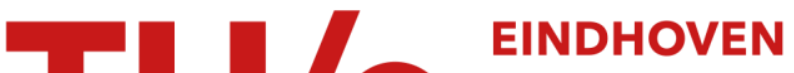 UNIVERSITY OF TECHNOLOGY
}

\section{Local lighting control in open-plan offices: the influence of office lay-out}

\section{Citation for published version (APA):}

de Bakker, C., Aarts, M. P. J., Kort, H. S. M., Meier, A., \& Rosemann, A. L. P. (2018). Local lighting control in open-plan offices: the influence of office lay-out. In T. Alexander, S. Bagnara, R. Tartaglia, S. Albolino, \& Y. Fujita (Eds.), Proceedings of the 20th Congress of the International Ergonomics Association (IEA 2018): Volume $X$ : Auditory and Vocal Ergonomics, Visual Ergonomics, Psychophysiology in Ergonomics, Ergonomics in Advanced Imaging (pp. 97-106). (Advances in intelligent systems and computing. AISC; Vol. 827). Springer. https://doi.org/10.1007/978-3-319-96059-3_10

DOI:

10.1007/978-3-319-96059-3_10

Document status and date:

Published: $27 / 08 / 2018$

\section{Document Version:}

Accepted manuscript including changes made at the peer-review stage

\section{Please check the document version of this publication:}

- A submitted manuscript is the version of the article upon submission and before peer-review. There can be important differences between the submitted version and the official published version of record. People interested in the research are advised to contact the author for the final version of the publication, or visit the $\mathrm{DOI}$ to the publisher's website.

- The final author version and the galley proof are versions of the publication after peer review.

- The final published version features the final layout of the paper including the volume, issue and page numbers.

Link to publication

\section{General rights}

Copyright and moral rights for the publications made accessible in the public portal are retained by the authors and/or other copyright owners and it is a condition of accessing publications that users recognise and abide by the legal requirements associated with these rights.

- Users may download and print one copy of any publication from the public portal for the purpose of private study or research.

- You may not further distribute the material or use it for any profit-making activity or commercial gain

- You may freely distribute the URL identifying the publication in the public portal.

If the publication is distributed under the terms of Article 25fa of the Dutch Copyright Act, indicated by the "Taverne" license above, please follow below link for the End User Agreement:

www.tue.nl/taverne

Take down policy

If you believe that this document breaches copyright please contact us at:

openaccess@tue.nl

providing details and we will investigate your claim. 


\title{
Local lighting control in open-plan offices: the influence of office lay-out
}

\author{
Christel de Bakker ${ }^{1}$, Mariëlle Aarts ${ }^{1}$, Helianthe Kort $^{1,2}$, Alan Meier ${ }^{3}$, and Alexander \\ Rosemann $^{1}$ \\ ${ }^{1}$ Eindhoven University of Technology, Rondom 70, 5600 MB Eindhoven, The Netherlands \\ ${ }^{2}$ Utrecht University of Applied Sciences, Heidelberglaan 7, 3584 CJ Utrecht, The Netherlands \\ ${ }^{3}$ Lawrence Berkeley National Laboratory, 1 Cyclotron Road, Berkeley, CA 94720, The United \\ States \\ c.d.bakker@tue.nl
}

\begin{abstract}
Highly granular lighting control involves switching on and off luminaires based on individual occupancy. The resulting high frequency of lighting changes can distract the office workers and negatively impact their work performance. In a cubicle office, this might be less of an issue than in an office without partitions, as users do not have an overview over the space here. We tested this control strategy in both office types and compared the results to determine the influence of office lay-out on the amount and acceptability of distractions that it poses. Our results indicated the opposite: occupants in the cubicle office were more often distracted and rated the distractions as less acceptable than in the bullpen office. As the job function types varied and the bullpen was consequently more dynamic, it seems that the type of work environment is of larger influence on users' satisfaction with local lighting control. However, more research is required to confirm this finding.
\end{abstract}

Keywords: distraction; occupancy-based lighting control; user satisfaction; energy efficiency; work performance

\section{Introduction}

The open-office environment has received much criticism over the years because it has been identified to negatively impact occupants' satisfaction with the work environment. Research identified noise and loss of privacy as the main sources causing this dissatisfaction $[1,2]$. Satisfaction with lighting is typically not an issue in open-plan offices; its quality is more important to office workers in enclosed offices. However, the transition from enclosed to open offices has affected offices' energy consumption for lighting, as in these large offices it is more complicated to apply occupancy-based lighting control. In an enclosed, private office, one occupancy sensor suffices to determine the presence of the single worker and control the luminaires in the room accordingly. In open-plan offices, however, lighting control at this individual level requires a finegrained sensor network. Although smart luminaires tends to be equipped with occupancy sensors, these just start to being implemented. In addition, luminaires and desks 
are typically not aligned in open-plan offices, hence some luminaires are also shared by multiple occupants, which complicates the design of highly granular lighting control. As a result, central lighting control tends still to be applied in open-plan offices.

Nevertheless, we find success stories of this type of lighting control in large office spaces, but they originate from studies in cubicle types; they showed energy savings of $41 \%$ and $60 \%[3,4]$. In these offices, luminaires and desks are aligned; as partitions limit the distribution of lighting from neighboring luminaires to surrounding desks, this alignment is required to provide occupants with sufficient illuminance. Hence, utilizing highly granular lighting control, or "local lighting control”, entails less difficulties here, and is already being applied.

These studies evaluated local lighting control with occupants in a real office; the majority of them expressed satisfaction with the provided lighting conditions. However, they did not measure whether it distracted them from their work activities. With local lighting control, each time occupants arrive at or leave their desks leads to a change in the lighting situation. The respective luminaire is switched on or off, which occupants could perceive as distracting.

We studied this issue in an open-plan office without partitions (so-called bullpen office) [5]. The majority of occupants did not consider lighting changes due to vacancies as unacceptable; to a few users, however, they did. When comparing the acceptability ratings to those from other environmental sources, electric lighting scored the lowest, together with sound, and was rated on average as "just acceptable”. Although the sample size of this study was limited, it suggests that this issue deserves further attention.

In cubicle offices, the lighting changes might be less noticeable to occupants as their view is blocked by partitions, and, as a result, less distracting. However, it is important to validate this hypothesis as distractions can negatively influence the work performance, as for example was found to be the case with noise [6]. In particularly in the open-plan office, it is highly undesirable that electric lighting poses another form of distraction as it already is perceived as a challenging environment to work in. In addition, employees form the major expense of companies; hence, their satisfaction cannot be endangered. Hence, user acceptance is highly important for the successful implementation of a strategy.

This motivated the replication of the bullpen study in a cubicle office, investigating the influence of office lay-out on users' perception of lighting changes. We chose to perform the cubicle study in Northern America, as they form the typical office lay-out here. The bullpen office was located in Northern Europe; hence, the results will also indicate whether cultural differences underlie lighting perception, which is also relevant for the transferability of other lighting control strategies across these continents. 


\section{Methodology}

\subsection{Study design}

The study in the cubicle office was conducted in January 2018 for three weeks; the European study had the same length in the same season (February 2016). We chose the winter season to minimize the influence of daylight. The cubicle testbed was located in Berkeley, California, the US, while the study in the bullpen office took place in the Netherlands. We first created a baseline through applying central manual lighting control for a week, followed by two variations of local lighting control, both for a week. We used a repeated measures design; participants experienced all three strategies.

\section{$2.2 \quad$ Lighting control design}

With the central manual control strategy, all luminaires were switched on by the occupant who arrived first in the office and switched off by the one who left the office the latest. We employed a time delay of five minutes during the first week local lighting control was tested, meaning that luminaires were turned off five minutes after occupants were detected to have left their cubicle. In the second week, this setting was changed to two minutes.

In the cubicle office, luminaires could already be controlled separately. Motion sensors above each desk allowed us to detect individual occupancy changes. In the open-plan office, off-the-shelve, plug-in switching nodes were placed at each luminaire, enabling them to be switched on and off separately. In addition to motion sensors, chair sensors were used in this office. More detailed information about this setup is reported in Labeodan, De Bakker, Rosemann, \& Zeiler (2016).

In the open-plan office, local lighting control in the first week (local lighting control 1) involved that each luminaire was only attributed to one occupant, while in the second week all luminaires required to provide 500 lx horizontally on the desk of the occupant were switched on. In the cubicle office, we employed the same commissioning across the two weeks of testing local lighting control: all luminaires that contributed significantly to the horizontal illuminance on the desk of the occupant were controlled by the occupant's sensor. This resulted in the use of one or two luminaires per occupant. We used a Konica Minolta illuminance meter for these measurements.

\subsection{Participants}

The open-plan office space was shared by twelve occupants; nine agreed to participate (all male; median age category 40-49 years old). Their job function types were all technical and required much cooperation; work activities consisted of discussing, technical drawing, and planning. The cubicle office contained 17 workplaces; 11 occupants par- 
ticipated (7 male, 4 female; median age category 30-39 years old). They all held a research job function type and mainly performed individual computer work. In this office, two occupants opted out (halfway the second and third week, respectively). All participants signed an informed consent before participation; it explained the general set-up of the experiment, including that a new control strategy would be applied during the second and third week.

\section{$2.4 \quad$ Experimental space}

Fig. 1 and Fig. 2 show the lay-out of the open-plan and cubicle office, respectively. The open-plan offices was an enclosed space, while the cubicle offices were located in a larger space with additional cubicles on the right hand while surrounded by perimeter offices. It was equipped with pendant luminaires with T5HO 4-foot LED lamps (54 W). In the open-plan office, luminaires were ceiling-based $(31 \mathrm{x})$, each containing $2 * 36 \mathrm{~W}$ linear fluorescent lamps.

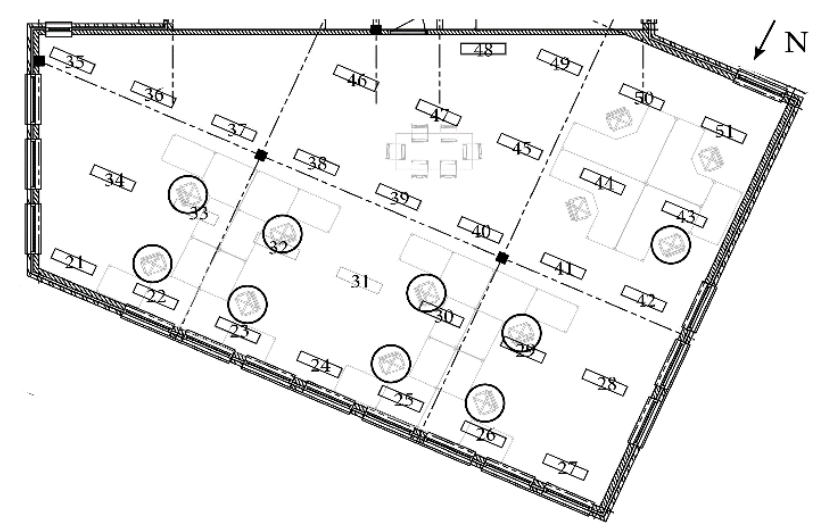

Fig. 1. Bullpen testbed with the luminaires numbered and the location of the participants circled (in the Netherlands) 


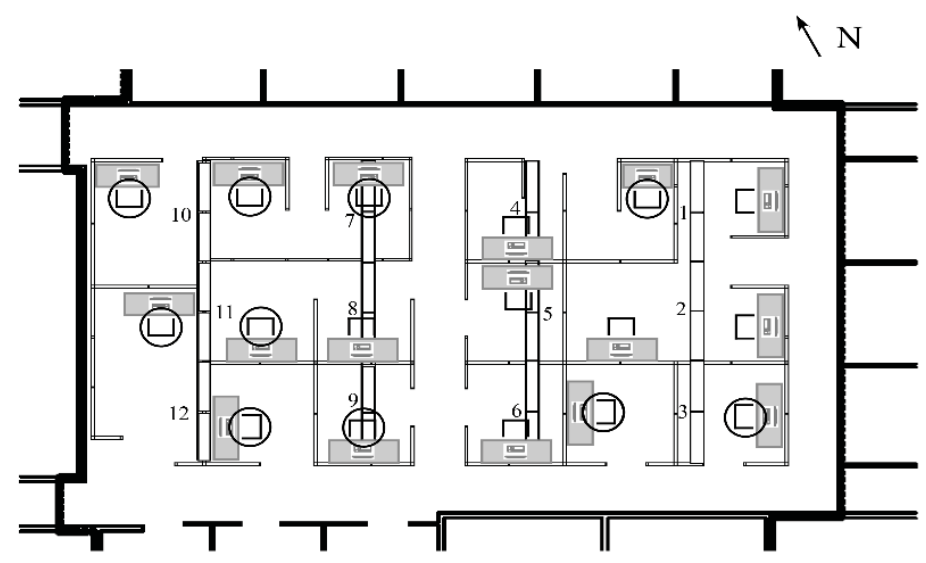

Fig. 2. Cubicle testbed with the luminaires numbered and the location of the participants circled (in the US)

\section{$2.5 \quad$ Procedure}

Before the start of the experiment, participants filled out a general survey assessing possible confounding variables. Surveys assessing distraction were distributed at Friday afternoon of each testing week. In the cubicle office, they were given the option to fill out this weekly questionnaire and a diary, or only a diary; four participants agreed to fulfil both. All participants in the open-plan office filled out the diary.

\subsection{Measures}

Distraction. The dependent variables (DV) included frequency of noticed change, frequency of distraction, and acceptability of distraction due to electric lighting. These three items were also assessed for six other environmental sources, namely 'Temperature', 'Odour', 'Ventilation', 'Occupancy', 'Sound', and 'Sunlight'. To assess them, we developed questions ourselves: "How often did you notice a change" and "How often did you got distracted" (answer options: never, sometimes, regularly, often, or always), and "If you got distracted, to which extent was this acceptable to you" (7-point Likert scale from Completely unacceptable to Completely acceptable), respectively. They were included in the weekly survey. This study does not report the three scores of the other environmental sources.

Possible confounding variables. In the pre-test survey, we assessed gender, age category, and vision (whether one wears glasses or contact lenses) as demographic characteristics. In addition, we assessed five other possible confounding variables: (1) productivity [8], (2) self-assessed general distraction, (3) privacy desire [9], (4) effect of environment on productivity [8], and (5) light sensitivity, using three items regarding light exposure sensitivity [10], with Cronbach's $\alpha=.536$. The weekly questionnaire started 
with a question regarding their concentration ability (four items: difficulties to concentrate, difficulties making choices, memory lapses, and difficulties to think clearly) on a 5 -point Likert scale from Never to Always, Cronbach's $\alpha=$.761).

\subsection{Analysis}

In this paper, we compared the results from the weekly questionnaires regarding distraction between the occupants of the two office types. First, we compared the two cases on the potential confounding variables.

Preparatory analyses. We detected significant correlations $>.30$ between the DV and three confounding variables: (1) age, correlating with frequency of distraction and acceptability of distraction, and (2) concentration ability, with frequency of distraction.

Distraction analyses. To determine the differences between the two office cases, we used descriptive statistics and employed the ANCOVA procedure with frequency of noticed change, frequency of distraction, and acceptability of distraction due to electric lighting as DV, and the confounding variables correlating with the DV as covariates. Normality tests showed that the data was close enough to normality to use this parametric test.

\section{$3 \quad$ Results}

Fig. 3, Fig. 4, and Fig. 5 report the Estimated Marginal Means (EMMs) of frequency of noticed change, frequency of distraction, and acceptability of distraction due to electric lighting, respectively, for both office cases and the three control strategies.

Fig. 3 shows that with central lighting control, occupants also noticed some lighting changes, while all lighting remained switched on the entire day. Occupants of both offices noticed an increased number of times changes in electric lighting when local lighting control was applied; on average, they reported this to occur "often". This increase was relatively higher in the cubicle office. We found significant effects for both office type and control strategy (see Table A1 in the Appendix), but not for the interaction effect between these two factors, which was of main interest to us.

Fig. 4 teaches us that occupants in the cubicle office were more than "sometimes' distracted by the lighting changes that they noticed when local lighting control was applied. In the bullpen office, the frequency of distraction declined over the three weeks, suggesting an adaptation effect. Here neither the interaction effect nor any of the main was not significant (see Table A1 in the Appendix).

Fig. 5 clearly indicates occupants in the cubicle office considered the distractions from local lighting control unacceptable, on average, while the participants from the bullpen 
office considered them acceptable. In both offices, the score increased during the second week of local lighting control, providing another indication for an adaptation effect. The differences between the two office types were not significant (see Table A1 in the Appendix).

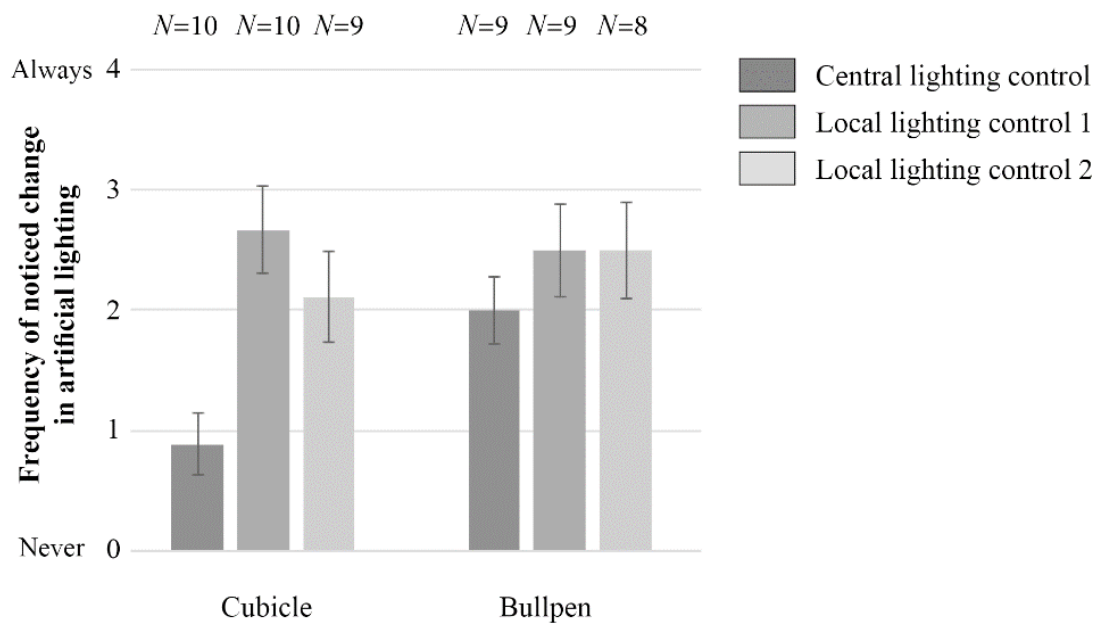

Fig. 3. Frequency of noticed change due to electric lighting with central lighting control, local lighting control 1, and local lighting control 2 in the cubicle and bullpen office. Acceptability scores are displayed as EMM's and error bars as SE's resulting from the ANCOVA post hoc analyses.

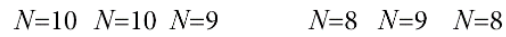

Always 4

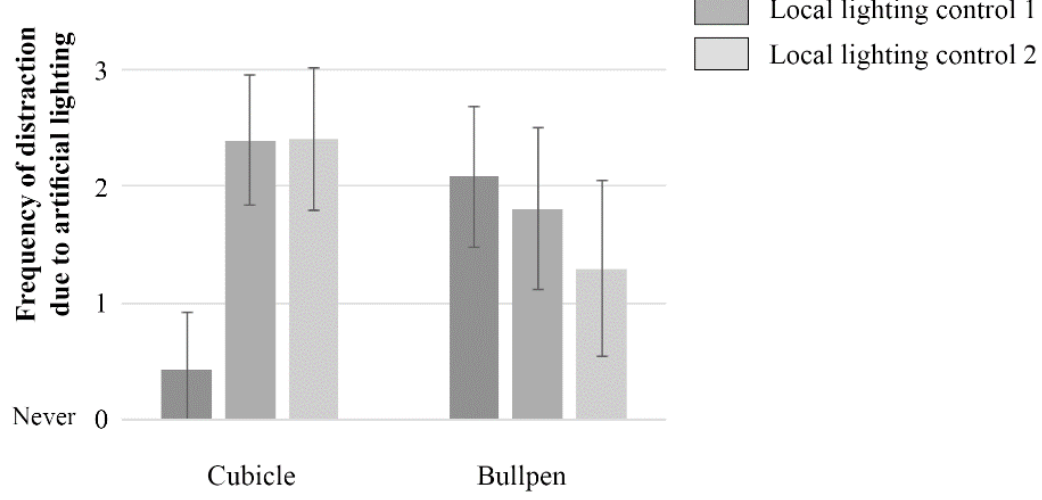


Fig. 4. Frequency of distraction due to electric lighting with central lighting control, local lighting control 1, and local lighting control 2 in the cubicle and bullpen office. Acceptability scores are displayed as EMM's and error bars as SE's resulting from the ANCOVA post hoc analyses.

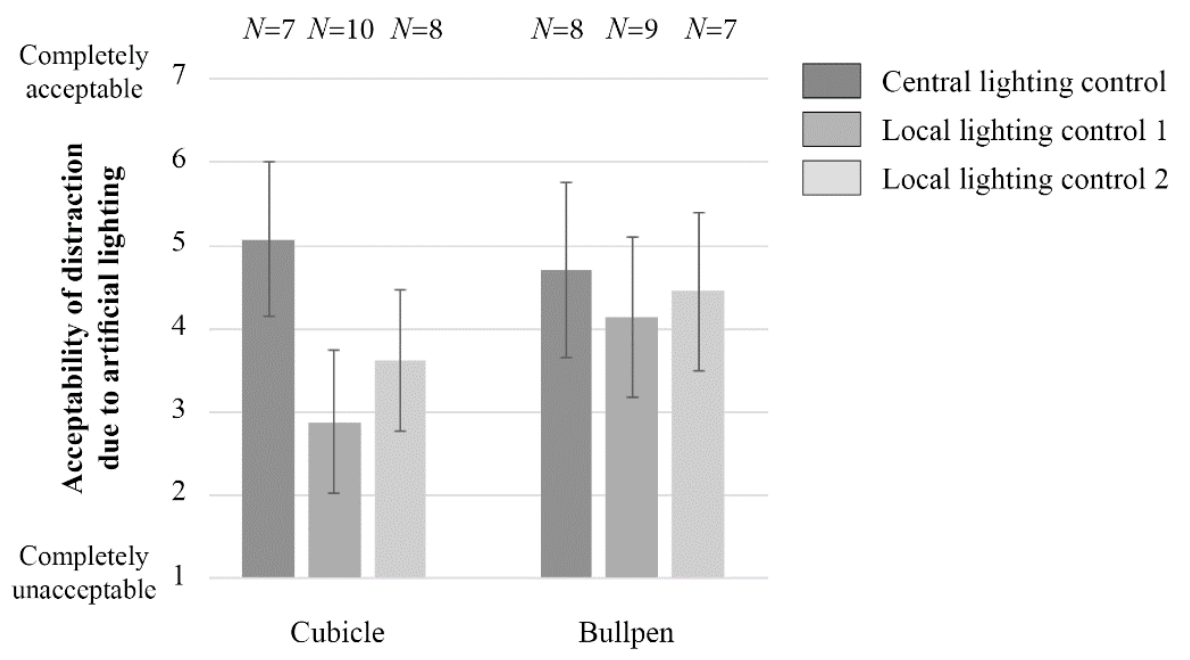

Fig. 5. Acceptability of distraction due to electric lighting with central lighting control, local lighting control 1, and local lighting control 2 in the cubicle and bullpen office. Acceptability scores are displayed as EMM's and error bars as SE's resulting from the ANCOVA post hoc analyses.

\section{Discussion}

Overall, our results suggest that the dynamic lighting conditions resulting from local lighting control were acceptable to the office workers of the bullpen office, but unacceptable to the participants in the cubicle office, while we expected the opposite.

First of all, when comparing the number of notice lighting changes between the two office cases, we see similar scores, while we expected the occupants of the cubicle office to less often notice them. In addition, occupants of the open-plan office were less often distracted by these changes, and evaluated them as more acceptable. This difference was not significant, but this is probably due to the large individual variability and small sample size. The two office cases were representative of the typical office layout, but had a different type of work environment, which can explain the unexpected results. In the open-plan office, interactions between occupants occurred very often, resulting in a highly dynamic environment. Occupants of the cubicle office had a more individualistic way of working; consequently, occurrences of any kind attract more attention. In addition, occupants of the open-plan office were used to changes in sunlight, as it had windows all along the façade. The cubicle offices, in contrast, were not exposed to direct sunlight. Our results suggest that the influence of office lay-out is less 
important on distractions posed by local lighting control than the type of work environment.

It has to be noted that the two office cases involved different type of occupancy sensors leading to different control behavior on false-offs. More false offs occurred in the cubicle office; that might have contributed to the lower acceptability scores here. It also caused the drop-out of the two occupants in the cubicle office. Thus, for local lighting control to succeed, it is highly important that suitable sensors are being used providing accurate information on occupancy.

In both offices, occupants got adapted to the lighting changes, resulting in higher acceptability scores during the second week. This also means that the shorter time delay applied during this week was not causing dissatisfaction, which is a highly positive finding for energy savings.

In addition to the weekly survey, we asked occupants to keep a diary about all moments they were distracted by any environmental source. However, only four participants of the cubicle test-bed agreed to fill-out this, so we did not use this data.

\section{Conclusion}

When applying highly granular lighting control in open-plan offices, the lighting levels change due to other co-workers leaving or arriving at their desk. Our study showed that these are being noticed by occupants, independently of office lay-out. They were sometimes considered distracting, but accepted by the occupants after a week of adaption time. Nevertheless, they were on average considered unacceptable by the occupants of the cubicle office, while the bullpen occupants evaluated them acceptable. This difference was insignificant, but before any conclusion can be drawn, a follow-up study is required where the type of work environment, meaning job function type and the amount of interactions are similar. This seemed to affect users' acceptance of distraction due to electric lighting changes instead of office type.

\section{Appendix}

Table A1. Results from ANCOVA with frequency of noticed change, frequency of distraction, and acceptability of distraction as dependent variables (DV)

\begin{tabular}{lccccccccc}
\hline & DV & \multicolumn{1}{l}{ Frequency of noticed change } & \multicolumn{3}{c}{ Frequency of distraction } & \multicolumn{4}{c}{ Acceptability of distraction } \\
\hline Effect & $d f$ & $F$ & $p$-value & $d f$ & $F$ & $p$-value & $d f$ & $F$ & $p$-value \\
Control strategy & $\mathbf{2}$ & $\mathbf{4 . 6 6}$ & $\mathbf{. 0 1 7 *}$ & 2 & 1.34 & .285 & 2 & .009 & .991 \\
Office type & $\mathbf{1}$ & $\mathbf{5 . 1 3}$ & $\mathbf{. 0 4 *}$ & 1 & .001 & .983 & 1 & .331 & .581 \\
Age category & - & - & - & 1 & 1.401 & .264 & 1 & .864 & .380 \\
Concentration ability & - & - & - & 1 & .375 & .554 & - & - & - \\
Control strategy * & 2 & 1.36 & .273 & 2 & 3.43 & .052 & 2 & .361 & .702 \\
Office type & & & & & & & &
\end{tabular}




\begin{tabular}{|c|c|c|c|c|c|c|c|c|}
\hline $\begin{array}{l}\text { Control strategy * } \\
\text { Age category }\end{array}$ & - & - & - & 2 & 1.73 & .202 & 2 & .047 \\
\hline $\begin{array}{l}\text { Control strategy * } \\
\text { Concentration ability }\end{array}$ & - & - & - & 2 & .95 & .404 & - & - \\
\hline
\end{tabular}

\section{Acknowledgements}

This work was in part funded by a Fulbright fellowship. It was also supported by the Assistant Secretary for Energy Efficiency and Renewable Energy, Building Technologies Office, of the U.S. Department of Energy under Contract No. DE-AC02$05 \mathrm{CH} 11231$.

\section{References}

1. de Croon EM, Sluiter JK, Kuijer PPFM, Frings-Dresen MHW (2005) The effect of office concepts on worker health and performance: A systematic review of the literature. Ergonomics 48:119-134

2. Bodin Danielsson C, Bodin L (2009) Difference in satisfaction with office environment among employees in different office types. J Archit Plan Res J Archit Plan Res 26:2412573

3. Rubinstein F, Enscoe A (2010) Saving energy with highly-controlled lighting in an open-plan office. LEUKOS 7:21-36 . doi: 2010.07.01002

4. Galasiu A, Newsham G, Suvagau C, Sander D (2007) Energy saving lighting control systems for open-plan offices: a field study. Leukos

5. de Bakker C, Aarts M, Kort H, Rosemann A (2017) Local lighting control in open-plan offices: acceptable or distracting? In: Healthy Buildings 2017 Europe. Lublin, Poland, pp 1-2

6. Banbury S, Berry D (2005) Office noise and employee concentration: Identifying causes of disruption and potential improvements. Ergonomics 48:25-37 . doi: 10.1080/00140130412331311390

7. Labeodan T, De Bakker C, Rosemann A, Zeiler W (2016) On the application of wireless sensors and actuators network in existing buildings for occupancy detection and occupancy-driven lighting control. Energy Build 127: . doi: 10.1016/j.enbuild.2016.05.077

8. Oseland N, Hodsman P (2015) Planning for Psychoacoustics: A Psychological Approach to Resolving Office Noise Distraction

9. Kaya N, Weber MJ (2003) Cross-cultural differences in the perception of crowding and privacy regulation: American and Turkish students. J Environ Psychol 23:301-309 . doi: 10.1016/S0272-4944(02)00087-7

10. Smolders KCHJ, de Kort YAW, Cluitmans PJM (2012) A higher illuminance induces alertness even during office hours: Findings on subjective measures, task performance and heart rate measures. Physiol Behav 107:7-16 . doi: 10.1016/j.physbeh.2012.04.028 